\title{
Corrigendum \\ Expanding Our Understanding of Neurobiological Mechanisms of Resilience by Using Animal Models
}

Israel Liberzon and Dayan Knox

Neuropsychopharmacology (2012) 37, I558; doi:I0.1038/npp.2012.9

Correction to: Neuropsychopharmacology (2012) 37(2), 317-318; doi:10.1038/npp.2011.259

In this article, the citation referring to the manuscript, which is the object of commentary, has an error in listing the names of the authors. The citation to Cohen et al., 2011 should read: Cohen H, Liu T, Kozlovsky N, Kaplan Z, Zohar J, Mathé AA. The neuropeptide Y(NPY)-ergic system is associated with behavioral resilience to stress exposure in an animal model of posttraumatic stress disorder. Neuropsychopharmacology 37:350-363. 